\title{
Clinical pharmacy services are performed at several emergency wards in Denmark
}

\author{
Susie Vand ${ }^{1 *}$, Lene Juel Kjeldsen ${ }^{2}$, Trine Kart ${ }^{2}$ \\ From 4th Danish Emergency Medicine Conference \\ Roskilde, Denmark. 25-26 November 2011
}

\section{Background}

When establishing new emergency wards, the clinical pharmacy profession has been included at some hospitals with the aim of assisting in optimizing medication treatment for admitted patients. However, it is unknown to what extent clinical pharmacy is performed and at which hospitals. To develop a national strategy and improve communication about the effects of clinical pharmacy, the Danish hospital pharmacies have requested a description of existing clinical pharmacy activities at emergency wards. Hence, the aim of the study was to describe clinical pharmacy activities at emergency wards in Denmark.

\section{Methods}

To ensure a $100 \%$ response rate, a study group containing one member from each region in Denmark was established. The 10 hospital pharmacies in Denmark were contacted with questions regarding type and extent of clinical pharmacy performed by clinical pharmacists and pharmaconomists at emergency wards in Denmark as well as how the services were funded. Data were collected in December 2010.

\section{Results}

Logistic services were provided by all 10 hospital pharmacies to 20 emergency wards. These services included ordering of medication according to the wards' standard assortment and local medication recommendations, and were delivered by pharmaconomists. Clinical pharmacists provided services to 15 emergency wards by performing e.g.: medication reviews (14), addressing medication-related questions (13), and teaching physicians and nurses (5). Other tasks included monitoring electronic medication charts, reporting of adverse events, performing internal audits, acquiring patient medication histories, conducting medication reconciliation, attending conferences and performing patient interviews. At 11 wards, established contracts had been made regarding the clinical pharmacist services, while project activities were delivered to 4 wards. Funding came from the emergency wards, the hospital pharmacy, the hospital management or external funding.

\section{Conclusion}

The study showed that all hospital pharmacies delivered clinical pharmacy services to 20 emergency wards although the services provided varied in content and extent. Logistic clinical pharmacy services provided by pharmaconomists were performed at each of the 20 emergency wards, while a range of variable cognitive clinical pharmacy services were delivered by clinical pharmacists. The study may be used to develop a common concept for Danish clinical pharmacy at emergency wards.

\section{Author details \\ ${ }^{1}$ The Hospital Pharmacy Århus, Horsens Department, Horsens, Denmark. \\ ${ }^{2} \mathrm{SAFE}$, Amgros $\mathrm{I} / \mathrm{S}$, Copenhagen $\varnothing$, Denmark.}

Published: 16 April 2012

\section{doi:10.1186/1757-7241-20-S2-P9}

Cite this article as: Vand et al:: Clinical pharmacy services are performed at several emergency wards in Denmark. Scandinavian Journal of Trauma, Resuscitation and Emergency Medicine 2012 20(Suppl 2):P9.

\footnotetext{
* Correspondence: susievand@horsens.rm.dk

${ }^{1}$ The Hospital Pharmacy Århus, Horsens Department, Horsens, Denmark

Full list of author information is available at the end of the article
}

(C) 2012 Vand et al; licensee BioMed Central Ltd. This is an Open Access article distributed under the terms of the Creative Commons Attribution License (http://creativecommons.org/licenses/by/2.0), which permits unrestricted use, distribution, and reproduction in any medium, provided the original work is properly cited. 